\title{
The relationship between hepatocytes and small bowel after early and short food restriction: What the results show in morphometry
}

\author{
Makovicky $\mathrm{P}^{1}$, Tumova $\mathrm{E}^{2}$, Volek $\mathrm{Z}^{3}$, Arnone $\mathrm{JM}^{4}$, Samasca $\mathrm{G}^{5}$, Makovicky $\mathrm{P}^{6}$ \\ Laboratory of Veterinary Histopathology in Komarno, M. Urbana 2019/7, 94501 Komarno, Slovakia. \\ pmakovicky@email.cz
}

\begin{abstract}
The objective of this study was to evaluate the relationship between hepatocyte morphometry and small bowel architecture after early and short food restriction. Altogether 48 Hyplus broiler rabbits were divided into three groups. The control group was fed ad libitum (ADL) throughout the experiment (C). The first group were foodrestricted between 32 and 39 days of age, when the rabbits received $50 \mathrm{~g}$ of food per rabbit each day (R1). The second group was restricted between 32 and 39 days and the rabbits received $65 \mathrm{~g}$ of food per rabbit each day (R2). In 39 and in 81 days eight rabbits from all three groups were euthanized. The diameter of centrilobular, midzonal and periportal hepatocytes and the height of villi, the width of villi and the crypt depth were measured. The hepatocytes grew from centrilobular to perilobular part in the C group, but in the R1 and R2 group, an opposite trend was noticed. On day 39 and daye 81 the elevations of villi were the highest. Interestingly, the nadirs of the crypts were deepest in the C group compared to the R1 and R2 groups. Early short intensive food restriction may play a role in the prevention of liver diseases (Tab. 2, Ref. 20). Text in PDF www.elis.sk. Key words: fasting, liver, NAFLD, NASH, nutrition, small bowel.
\end{abstract}

\section{Introduction}

The results of current research demonstrate that food restriction is connected with gastrointestinal adaptation to changes in food intake $(1,2,3)$. The results of our previous experiments show that these changes are a result of limited levels of nutrition with relatively rapid adaptation to post-restriction period with ad libitum (ADL) intake (4). Noting the outcome of the preceding studies, the aim of this study was to examine the relationship between food restriction and gastrointestinal adaptation in the small bowel and hepatocytes. Moreover, we wanted to see if food restriction could be utilized as a means for liver disease prevention, for example, in non-alcoholic fatty liver disease (NAFLD). It is one of the most common liver disease throughout the world and includes simple steatosis, non-alcoholic steatohepatitis (NASH), liver fibrosis and liver cirrhosis. It was found that between nutrition and NAFLD

\footnotetext{
${ }^{1}$ Laboratory of Veterinary Histopathology in Komarno, Komarno, Slovakia, ${ }^{2}$ Department of Animal Husbandry, Faculty of Agrobiology, Food and Natural Resources, Czech University of Life Sciences in Prague, Prague, Czech Republic, ${ }^{3}$ Physiology of Nutrition and Quality of Animal Product, Institute of Animal Science in Prague - Uhrineves, Uhrineves, Czech Republic, ${ }^{4}$ School of Nursing, Kean University, Union New Jersey, United States, ${ }^{5}$ Department of Immunology, Iuliu Hatieganu University of Medicine and Pharmacy, Cluj-Napoca, Romania, and ${ }^{6}$ Department of Biology, Faculty of Science, Selye Janos University, Komarno, Slovakia
}

Address for correspondence: P. Makovicky, Ing, PhD, Laboratory of Veterinary Histopathology in Komarno, M. Urbana 2019/7, SK-945 01 Komarno, Slovakia.

Phone: +0420776842684

Acknowledgement: The work was supported by NAAR QJ15100192. development some relationships exist. Therefore, we assume that there exist some positive relationship between food restriction and liver morphology, including small bowel morphology. With morphometric assessment changes were observed in the diameter of hepatocytes, percentage content of interstitial tissue and hepatocytes and included some changes in the villi height and crypt depth between the ADL and food restricted groups. It is unknown however, how these changes affect the cells in other organs, or if some other physiological succession exists. The liver is one of the largest organs of the gastrointestinal tract. It is well known that the liver acinus is the smallest functional unit of liver parenchyma and three distribution zones were defined. Classification is often used in histopathology description. The periportal zone was the first zone to receive oxygen, and nutrition. This was followed by repeating the receipt of oxygen and nutrition to the midzonal zone and last, to the centrilobular zone (5). That the relationship between food restriction, height of villi, width of villi, depth of crypts of the small bowel and saturation of the hepatocytes differ among the three zones of the liver acinus. It is currently known that these types of changes are also the result of food intake. What is not currently known is what the connections are after food restriction and during a post-restriction period with ADL intake. Furthermore, it is also not known if some relationships exist between liver acinus, hepatocytes and small bowel morphology in this process. The answers to these questions will help to shed light on the interaction between the small bowel and the liver during normal and short food restriction under experimental conditions. The information can then be used in future research studies. Relationships between organs in the development of the diseases could in the future generate attention in the search for marches in the disease diagnosis at 
the initial stage as well as on the therapeutic aspects. The objective of this study was to evaluate the relationship between hepatocyte morphometry and small bowel architecture after early and short food restriction in an experimental rabbit model.

\section{Material and methods}

\section{Ethics}

This study was approved by the Ethics Committee of the Institute of Animal Science and the Central Commission for Animal Welfare of the Ministry of Agriculture of the Czech Republic and carried out according to the guidelines for applied nutrition experiments in rabbits (6).

\section{Animals, diet and experimental design}

A total of 48 Hyplus broiler rabbits were included in this study. All animals were kept under controlled environmental conditions (room temperature between 16 to $18{ }^{\circ} \mathrm{C}$, relative humidity of 60 $\%, 12$ hour of light per day and space of $0.16 \mathrm{~m}^{2}$ per rabbit). The experiment was conducted in the rabbit compartment of the Institute of Animal Science from a weaning age of 25 to 81 days. The rabbits were divided into three groups, each containing 8 animals. The control group of rabbits was fed ad libitum (ADL) throughout the experiment $(\mathrm{C})$. The first group was food-restricted between 32 and 39 days of age, when the rabbits received $50 \mathrm{~g}$ of food per rabbit each day (R1). The second group was also restricted between 32 and 39 days, but the rabbits received $65 \mathrm{~g}$ of food per rabbit each day (R2). Before and after food restriction, the rabbits of both, R1 and R2 groups were fed ADL. At the end of the restriction in 39 days, eight rabbits from all three groups were randomly selected to be euthanized for post mortem study. Remaining 24 rabbits (eight per all C, R1 and R2 groups) were fed ADL to the end of the experiment. At the end of the experiment at 81 days of age, the remaining rabbits were also euthanized for post mortem study.

\section{Liver and small bowel sampling}

Samples were obtained during the necropsy. One sample was taken from the centre of the liver parenchyma and three samples (duodenum, jejunum and ileum) were taken from the small bowel from each animal. The samples were fixed with a Bouin solution and transported to the histopathological laboratory. All samples were collected within 30 minutes after the euthanasia and they were fixed for 24 hours.

\section{Histology and morphometric measurements}

The samples were processed by standard histological methods. Three to five $\mu \mathrm{m}$ thick slices were cut from each sample, and afterwards the slices were stained with haematoxylin-eosin (DiaPath, Italy). The prepared samples were evaluated in a microscopic picture using Olympus microscope (Olympus Provis BX40, Japan). The evaluation consisted of morphometry measurement using the NIS-Elements AR version 3.0 software (Laboratory Imaging s.r.o., Czech Republic). Visualization of the centrilobular, midzonal and periportal regions of the liver acinus was distinguished separately and the diameters of the hepatocytes in each part were measured.
Altogether 150 measurements were done per each liver ( 50 centrilobular, 50 midzonal and 50 periportal measurements). The height of the villus was measured from the top of the villus to the crypt transition. The width of villi was measured from the middle of the villus and the crypt depth was defined as the invagination between two villi. In total, the heights of 150 villi, the width of 150 villi and the depths of 150 crypts were measured (50 per duodenum, 50 per jejunum and 50 per ileum) per each small bowel.

\section{Statistical analysis}

The results were evaluated by analysis of variance, using the SAS program. Differences between groups were evaluated by Duncan's test. The differences were considered to be significant if $\mathrm{p}<0.05$.

\section{Results}

\section{The diameter of hepatocytes}

Immediately after food restriction at the 39th day mark, there were some differences between the diameters of the hepatocytes in the groups. The largest diameter of the hepatocytes was measured in the C group $(18.45 \mu \mathrm{m})$ and the smallest in the R1 group $(15.98 \mu \mathrm{m})$. The R2 groups had average of hepatocytes between first two groups $(17.71 \mu \mathrm{m})$. A similar trend was also found at the end of experiment at the 81 st day mark. The diameter of all of the hepatocytes grew in size, with the largest diameter measuring 23.16 $\mu \mathrm{m}$ from the $\mathrm{C}$ group. In the $\mathrm{R} 1, \mathrm{R} 2$ groups there were also visible increases noted in the diameter of the hepatocytes (R1: $21.76 \mu \mathrm{m}$ and R2 $21.91 \mu \mathrm{m})$. These results however, were not statistically significant $(\mathrm{p}>0.05)$. The results of wider morphometry showed some regularities. At the 39th day mark, all groups demonstrated similar trends with the largest diameter of the hepatocytes residing in the centrilobular part and the smallest diameter of the hepatocytes in the periportal part of the liver acinus. At the end of the experiment at the 81 st day mark there were some changes in this trend. In the $\mathrm{C}$ group the trend remained preserved, but in the experimental groups there were some visible changes noted. In the R1 and R2 group, the diameter of the hepatocytes was the smallest in the centrilobular part as compared to the midzonal and periportal regions. However, the midzonal region continued to show hepatocytes with the largest diameters (Tab. 1).

Tab. 1. The results of hepatocyte morphometry.

\begin{tabular}{lccc}
\hline Indicator & Part of the & \multicolumn{2}{c}{ Diameter of the hepatocytes $(\mu \mathrm{m})$} \\
\cline { 4 - 4 } \cline { 4 - 4 } Group & liver lobule & 39 days old & 81 days old \\
\hline \multirow{3}{*}{$\mathrm{C}$} & Centrilobular & 19.24 & 24.13 \\
& Midzonal & 18.4 & 22.91 \\
& Periportal & 17.7 & 22.44 \\
\hline \multirow{3}{*}{$\mathrm{R} 1$} & Centrilobular & 16.14 & 20.72 \\
& Midzonal & 16.11 & 23.61 \\
& Periportal & 15.68 & 20.96 \\
\hline \multirow{2}{*}{ R2 } & Centrilobular & 19.62 & 21.3 \\
& Midzonal & 16.69 & 22.5 \\
& Periportal & 16.81 & 21.94 \\
\hline
\end{tabular}

$\mathrm{C}$ - control group, R1 - restriction to $50 \mathrm{~g}$ of food per rabbit/per day, R2 - restriction to $65 \mathrm{~g}$ of food per rabbit/per day $(\mathrm{p}<0.05)$ 
Tab. 2. The results of small bowel morphometry.

\begin{tabular}{|c|c|c|c|c|}
\hline Group & $\begin{array}{l}\text { Part of the } \\
\text { small bowel }\end{array}$ & $\begin{array}{c}\text { Indicator } \\
(\mu \mathrm{m})\end{array}$ & 39 days old & 81 days old \\
\hline \multirow{3}{*}{$\mathrm{C}$} & \multirow{3}{*}{ Duodenum } & Height of the villi & 588.75 & 590.08 \\
\hline & & Width of the villi & 80.86 & 93.01 \\
\hline & & Depth of the crypt & 93.97 & 100.4 \\
\hline \multirow{3}{*}{$\mathrm{C}$} & \multirow{3}{*}{ Jejunum } & Height of the villi & 306.58 & 490.49 \\
\hline & & Width of the villi & 65.19 & 82.78 \\
\hline & & Depth of the crypt & 73.44 & 105.84 \\
\hline \multirow{3}{*}{$\mathrm{C}$} & \multirow{3}{*}{ Ileum } & Height of the villi & 282.79 & 377.86 \\
\hline & & Width of the villi & 66.86 & 81.72 \\
\hline & & Depth of the crypt & 69.39 & 85.85 \\
\hline \multirow{3}{*}{ R1 } & \multirow{3}{*}{ Duodenum } & Height of the villi & 533.96 & 529.92 \\
\hline & & Width of the villi & 69.61 & 82.29 \\
\hline & & Depth of the crypt & 90.95 & 100.92 \\
\hline \multirow{3}{*}{ R1 } & \multirow{3}{*}{ Jejunum } & Height of the villi & 284.96 & 360.88 \\
\hline & & Width of the villi & 55.83 & 77.39 \\
\hline & & Depth of the crypt & 69.62 & 90.11 \\
\hline \multirow{3}{*}{ R1 } & \multirow{3}{*}{ Ileum } & Height of the villi & 277.03 & 362.39 \\
\hline & & Width of the villi & 53.78 & 83.42 \\
\hline & & Depth of the crypt & 57.02 & 94.73 \\
\hline \multirow{3}{*}{ R2 } & \multirow{3}{*}{ Duodenum } & Height of the villi & 391.54 & 355.79 \\
\hline & & Width of the villi & 53.17 & 78.7 \\
\hline & & Depth of the crypt & 61.17 & 93.3 \\
\hline \multirow{3}{*}{ R2 } & \multirow{3}{*}{ Jejunum } & Height of the villi & 260.8 & 290.96 \\
\hline & & Width of the villi & 58.1 & 71.46 \\
\hline & & Depth of the crypt & 59.87 & 60.98 \\
\hline \multirow{3}{*}{$\mathrm{R} 2$} & \multirow{3}{*}{ Ileum } & Height of the villi & 250.01 & 450.89 \\
\hline & & Width of the villi & 56.13 & 78.56 \\
\hline & & Depth of the crypt & 59.44 & 94.18 \\
\hline
\end{tabular}

$\mathrm{C}$ - control group, $\mathrm{R} 1$ - restriction to $50 \mathrm{~g}$ of food per rabbit/per day, $\mathrm{R} 2$ - restriction to $65 \mathrm{~g}$ of food per rabbit/per day

\section{The height of the villi}

Table 2 shows the results of the small bowel morphometry. Immediately at the end of the food restriction on the 39th day, the height of villi was highest in the $\mathrm{C}$ group compared with the R1 and R2 groups. The results were statistically significant in the $\mathrm{C}$ and R2 groups $(\mathrm{p}<0.05)$. At the 81 st day mark, similar trends were noted. The results demonstrated that the highest villi height occurred in the $\mathrm{C}$ group, as compared to the R1 and R2 groups ( $\mathrm{p}$ $<0.05$ ). Visualization of the small bowel showed some relationships between the duodenal, jejunal, and ileal part of the small bowel and groups. The height of villi was the highest in the duodenal part including C, R1 and R2 groups. However, the smallest heights were observed in the ileal part of all groups. At the end of experiment at the 81 st day mark, there were some notable visible differences. The duodenal part had highest villi in the $\mathrm{C}$ and $\mathrm{R} 1$ groups. In the R2 group, the ileal part had the highest villi. In the $\mathrm{C}$ group, there were similar trends observed at the end of experiment, which were analogous to the end of the food restriction. Findings showed that the highest villi elevations were noted in the duodenal part and the lowest elevations were observed in the ileal part. Yet, in the R1 part, the highest villi elevation was seen in the duodenal part and the lowest villi elevation was observed in jejunal part. Last, in the R2 group, the highest villi elevation was observed in the ileal part and lowest villi elevation was observed in the jejunal part.
The width of the villi

Comparing the results at the end of food restriction and at the end of the experiment, showed some similarities in the width of the villi. The widest villi measured were seen in the $\mathrm{C}$ group and the lowest villi width measured was observed in the $\mathrm{R} 2$ group. The results were statistically significant at the end of food restriction $(p<0.05)$ and at the end of the experiment $(p<0.05)$. Looking at the different parts of the small bowel and to the different groups, the results are balanced with the trends of the villi width growth in the ileal part of the small bowel at the end of experiment.

\section{The depth of the crypts}

Some similarities were noted in the measured depth of the crypts in the different groups at both the end of food restriction phase and at the end of experiment. The deepest crypts were consistently observed in the $\mathrm{C}$ group and the moss flatted always in the R2 group $(p<0.05)$. Observation and then comparison of the different parts of small bowel with the different groups demonstrated visibly intensive deepening of the jejunal and ileal crypts among all groups.

\section{Discussion}

The transport of blood crosses the liver acinus from the peripheral vessels to the central vein which impacts liver function. All incoming nutrients are first consumed by periportal hepatocytes and last by centrilobular hepatocytes. The same sequences are also applied to oxygen. For example, research studies have shown that in cirrhotic livers, the relative lack of oxygen in the centrilobular zone appears to encourage fibrosis in that zone. If there are too many fats present, and after they are initially consumed by the periportal and midzonal hepatocytes, the rest of fat is consumed by the centrilobular hepatocytes with centrilobular steatosis development $(7,8)$. Additionally, toxicology studies show the importance of blood flow across liver $(9,10)$. This interpretation demonstrates that a toxic substance first brought into contact with periportal hepatocytes, afterwards with midzonal and at last with centrilobular hepatocytes. This means that the portal hepatic pathology can result from acute poisoning. This information is important for biopsy practice. Current knowledge documented in the literature reports that during food restriction some changes are visible in the liver morphology (11). The mechanism for this process to occur is dependent on time, intensity and length of food restriction. Pathology may develop into liver steatosis as a result of uptake and storage of fat from the blood. Additionally, it is important to remark that the metabolism of other organs is also involved (12). The results of our study establish that the small bowel is also adjusted during this process as there were some visible villous architectonic changes observed. In the recent scientific literature there is not any concrete morphometric data about the relationship between small bowel architecture and morphometry of different hepatocytes in the liver acinus. Contrarily, some studies document connections between the small bowel and liver. In one study it was posited that obesity can be connected with neurotensin, which is predominantly localized in entero-endocrine cells of the small bowel(13). Another study shows that patients with 
intestinal failure commonly develop abnormal liver function tests (14). The authors document an adult patient with Crohn's disease and multiple small bowel resections in combination with developing liver dysfunction. Our results document that architecture of the small bowel can adapt to changes relatively easily with food restriction. Today it is well known that the length and width of the villi depend on the intensity of the nutrition. In our study all the rabbits at those restricted levels are receiving enough nutrients, so the changes observed are not only due to amounts of food and not to a deficiency in specific nutrients. This is an important issue to address, since the liver is very sensitive to micronutrient amounts and not only to macronutrients. Some studies document this is due to hepatocyte and epidermal growth factors causing enterocyte hypertrophy and hyperplasia $(15,16)$. On the other hand the liver responds more slowly, but the changes are more pronounced. Kong et al (17) report that fibroblast growth factor (FGF15) is expressed in the small intestine and plays a critical role in liver hepatic functions. So hypothetically, small bowel lengthening with hormone release can support liver regeneration. Simple steatosis begins in the centrilobular liver zone. The result of Molina-Aguilar et al (18) indicate that time-caloric restriction reduced hepatomegaly and prevented the increase in blood leukocytes promoted by diethylnitrosamine. Also effects of short food restriction on hepatocytes are visible, but the changes after ADL nutrition are more visible in our study. The periportal and midzonal hepatocytes are saturated first and centrilobular hepatocytes later. These facts document the physiological relationship between blood flow, incoming nutrition and the hepatocytes in the different zones of the liver acinus. Moreover, one study suggests that dietary and caloric restriction is beneficial in middle-aged or early senescent obese people (19). Our results also document that the short-term food restriction could be beneficial for the body. The hepatocytes metabolise excess fats during food restriction. During post-restrictive ADL nutrition, the perilobular and midzonal hepatocytes are saturated first and at the end the centrilobular parts are nutritioned. Here changes in lipid and carbohydrate metabolism certainly played an important role (20). As intracytoplasmatic hepatocyte fats were consumed, they were replaced by glycogen. During the post-restrictive ADL nutrition, it was observed that the first hepatocytes to store fat were the centrilobular hepatocytes. Therefore, early short intensive food restriction may play an important role in the prevention of liver diseases.

\section{References}

1. Ginter E. Vegetarian diets, chronic diseases and longevity. Bratisl Lek Listy 2008; 109 (10): 463-466.

2. Ginter E, Simko V. New data on harmful effects of trans-fatty acids. Bratisl Lek Listy 2016; 117 (5): 251-253.

3. Norizadeh Tazekhand M. Antiproliferative effects of a food coloring on colon cancer line. Bratisl Lek Listy 2017; 118 (5): 265-268.

4. Tumova E, Volek Z, Chodova D et al. The effect of 1-week feed restriction on performance, digestibility of nutrients and digestive system development in the growing rabbit. Animal 2016; 10 (1): 1-9.
5. Malarkey DE, Johnson K, Ryan L, Boorman G, Maronpot RR. New insights into functional aspects of liver morphology. Toxicol Pathol 2005; 33 (1): 27-34.

6. Fernandez-Carmona J, Blas E, Pascual JJ, Maertens L, Gidenne, T, Xiccato, G, Garcia, J. Recommendations and guidelines for applied nutrition experiments in rabbits. World Rabbit Sci 2005; 13 (4): 209-228.

7. Pataky Z, Genton L, Spahr L et al. Impact of hypocaloric hyperproteic diet on gut microbiota in overweight or obese patients with Nonalcoholic fatty liver disease: A pilot study. Dig Dis Sci 2016; 61 (9): 2721-2731.

8. Ramadori G, Saile B. Portal tract fibrogenesis in the liver. Lab Invest 2004; 84 (2): 153-159.

9. Rogers, H.; Zibari, G.B.; Roberts, J.; Turnage, R.; Lefer, D.J. Nitric oxide attenuates ischaemia-reperfusion (I/R) injury in the diabetic liver. Clin Transplant 2004; 18 (S12): S7-S11.

10. Sanchez-Polo MT, Castells MT, Garcia-Perez B, Martin A, Adanez G, Ayala I. Effect of diet/atorvastin on atherosclerosis lesions associated to non-alcoholic fatty liver disease in chickens. Histol Histopathol 2015; 30 (12): 1439-1446.

11. Grattagliano I, Portncasa P, Caraceni P, Palmieri VO, Domenicali M, Bernardi M, Palasciano G. Experimental observations and clinical implications of fasting and diet supplementation in fatty livers. Eur Rev Med Pharmacol Sci 2003; 7 (1): 1-7.

12. De Vries EM, van Beeren HC, Ackermans MT, Kalsbeek A, Fiers E, Boelen A. Differential effects of fasting vs food restriction on liver thyroid hormone metabolism in male rats. J Endocrinol 2015; 224 (1): 25-35.

13. Li J, Song J, Zaytseva YY et al. An obligatory role for neurotensin in high-fat-diet induced obesity. Nature 2016; 533 (7603): 411-415.

14. Hvas C, Kodjabashia K, Nixon E, Hayes S, Farrer K, Abraham A, Lal S. Reversal of intestinal failure-associated liver disease (IFALD): emphasis on its multifactorial nature. Frontline Gastroenterol 2016; 7 (2): 114-117.

15. Katz MS, Thatch KA, Schwartz MZ. Chronology of the effects of massive small bowel resection and hepatocyte growth factor (HGF) on intestinal adaptation. J Surg Res 2011; 171 (2): 399-403.

16. Walther A, Coots A, Nathan J, Kocoshis S, Tiao G. Physiology of the small intestine after resection and transplant. Curr Opin Gastroenterol 2013; 29 (2): 153-158.

17. Kong B, Huang J, Zhu Y et al. Fibroblast growth factor 15 deficiency impairs liver regeneration in mice. Am J Physiol Gastrointest Liver Physiol 2014; 306 (10): 893-902.

18. Molina-Aguilar C, de Jesus Guerrero-Carrillo M, Espinosa-Aguirre JJ et al. Time caloric restriction inhibits the neoplastic transformation of cirrhotic liver in rats treated with diethylnitrosamine. Carcinogenesis 2017; 38 (8): 847-850.

19. Goto S, Takahashi R, Radak Z, Sharma R. Beneficial biochemical outcomes of late-onset dietary restriction in rodents. Ann N Y Acad Sci 2007; 1100 (4): 431-441.

20. Pivko J, Makovicky P, Makarevich AV, Sirotkin AV, Makovicky P, Kubovicova E. Pathological alterations in hepatocytes of dairy cows with a tendency to emaciation and fattening. Folia Vet 2016; 60 (2): 53-60.

Received November 27, 2017. Accepted December 23, 2017. 